\title{
Evolution of thermo-mechanical properties of concrete with calcium aluminate cement and special aggregates for energy storage
}

\author{
Marta Roig-Flores ${ }^{\text {a, }}$, Tamara Lucio-Martin ${ }^{\text {a }}$, María Cruz Alonso ${ }^{\text {a }}$, Luis Guerreiro ${ }^{\text {b }}$ \\ ${ }^{a}$ Consejo Superior de Investigaciones Científicas, Instituto Eduardo Torroja de Ciencias de la Construcción (CSIC-IETcc), c/ Serrano Galvache, 4, 28033 Madrid, Spain \\ ${ }^{\mathrm{b}}$ University of Évora, Renewable Energies Chair, Casa Cordovil, Rua D. Augusto Eduardo Nunes, n.7, 7000-651 Évora, Portugal
}

\section{A R T I C L E I N F O}

\section{Keywords:}

Calcium aluminate cement

Concrete

Thermal cycles

Cracking

Thermal conductivity

\begin{abstract}
A B S T R A C T
With the ever-expanding presence of solar energy, the design of cost-efficient heat energy storage systems is becoming increasingly relevant. Concrete is a potential solid material for these systems but raises questions of its response at high temperatures in operating conditions. This work studies concrete designed with calcium aluminate cement and three types of aggregates that are stable at high temperatures. The designed concrete mixes were exposed to thermal cycles $\left(290-550{ }^{\circ} \mathrm{C}\right)$, and their thermal fatigue response was evaluated with mechanical, cracking, thermal, and microstructural analyses at room temperature after heat cycles. The obtained results show that the main changes are mostly produced after the first thermal cycle and are stabilized during successive thermal cycles, with only a slight decrease in the thermo-mechanical properties. The results showed stabilization of cracking, crack widths between 10 and $80 \mu \mathrm{m}$, reduction of compressive strength, around $50-65 \%$, and reduction of the thermal conductivity by $30 \%$.
\end{abstract}

\section{Introduction}

Energy consumption is growing every year, driving forward the burning of fossil fuels and thus increasing $\mathrm{CO}_{2}$ emissions and accelerating climate change. Energy consumption increased in 2017 by $2.2 \%$, being the fastest rate since 2013 , and $\mathrm{CO}_{2}$ emissions increased by $1.6 \%$ [1]. Given that, the development of cost-efficient harvesting combined with energy storage systems for renewable energies is a priority, with an increasing presence in the industry and research in the last years [2].

Solar Thermal Energy Storage (TES) systems have working temperature values between 120 and $600{ }^{\circ} \mathrm{C}$ [3], depending on the Heat Transfer Fluid (HTF) used. Currently, concrete is being explored as a potential material TES systems [4-9], presenting new challenges due to the decomposition of concrete compounds at temperatures above $105{ }^{\circ} \mathrm{C}$. Other applications in which concrete structures are exposed to similar temperatures during its life are the geothermal power plants for thermal energy storage elements and nuclear power plants, as well as those elements acting as thermal insulation. Concrete for TES systems will be exposed at the same temperature regime and thermal gradient than the HTF during the heat charge/discharge processes. In the case of molten salts, the temperature can range between the melting point and the maximum temperature without degradation of the salt, commonly
$290{ }^{\circ} \mathrm{C}$ and $550{ }^{\circ} \mathrm{C}[3,10,11]$. Recent studies have demonstrated the appropriateness of using the Solar Salt $\left(60 \% \mathrm{NaNO}_{3}, 40 \% \mathrm{KNO}_{3}\right)$ up to $600{ }^{\circ} \mathrm{C}$ [12]. For that reason, the higher the temperature of the HTF, the better the thermal resistance must the material display. For current refractory applications, three main strategies are being followed: 1) use of Ordinary Portland Cement (OPC) blended with pozzolana, 2) use of calcium aluminate cement (CAC), and 3) aggregates of specific properties and stability at high temperatures with suitable size distributions.

OPC hydrated compounds are Calcium Silicate Hydrates gels (CSH) and Calcium Hydroxide $(\mathrm{CH})$. $\mathrm{CSH}$ gels decompose at temperatures between 100 and $400{ }^{\circ} \mathrm{C}$, and $\mathrm{CH}$ decomposes between 400 and $500{ }^{\circ} \mathrm{C}$. One of the dehydrated products from $\mathrm{CH}$ and $\mathrm{CSH}$ is calcium oxide, $\mathrm{CaO}$. This calcium oxide is formed after the dehydration of the solid matrix, but it can rehydrate if exposed to atmospheric moisture, with different rates depending on the specific conditions [13]. The formation of new $\mathrm{CH}$ is an expansive process that introduces swelling risks into concrete elements. This swelling can produce the disintegration of the cement paste due to the pressures generated. OPC blended types of cement generate more $\mathrm{CSH}$ and less $\mathrm{CH}$, having less risk of swelling after dehydration [14-16].

In the case of CAC, the main hydrated compounds are Calcium Aluminate Hydrates $\mathrm{CAH}_{10}$ and $\mathrm{C}_{2} \mathrm{AH}_{8}$, and Aluminum Hydroxide

\footnotetext{
* Corresponding author at: Universitat Politècnica de València UPV-ICITECH, Camino Vera s/n, 46022 València, Spain.

E-mail address: marroifl@upv.es (M. Roig-Flores).
} 
Table 1

Summary of relevant properties at high temperatures for siliceous, calcareous and basalt aggregates and concrete with aggregates of each nature (values from $[14,19])$.

\begin{tabular}{|c|c|c|c|}
\hline \multirow[t]{2}{*}{ Type } & \multicolumn{2}{|c|}{ Properties of the aggregate individually } & \multirow{2}{*}{$\begin{array}{l}\text { Concrete } \\
\text { property }\end{array}$} \\
\hline & Microstructural changes & $\begin{array}{l}\text { Thermal } \\
\text { Expansion } \\
\text { Coefficient }\end{array}$ & \\
\hline Siliceous & $\begin{array}{l}\text { Between } 500 \text { and } 650{ }^{\circ} \mathrm{C} \\
\alpha \text {-quartz is transformed into } \\
\beta \text {-quartz, with expansions of } \\
1.0-1.4 \% \text { (reversible reaction) }\end{array}$ & $\begin{array}{l}10.3 \times 10^{-6} / \\
{ }^{\circ} \mathrm{C}\end{array}$ & $\begin{array}{l}1.8-3.9 \mathrm{~W} / \\
\mathrm{mK}\end{array}$ \\
\hline Calcareous & $\begin{array}{l}\text { Decarbonation at temperatures } \\
\text { between } 600 \text { and } 900{ }^{\circ} \mathrm{C} \text {. } \\
\text { Afterward, the free lime can be } \\
\text { re-hydrated, forming } \mathrm{CH} \text {, with } \\
\text { an increase of volume of } 44 \%\end{array}$ & $5.5 \times 10^{-6} /{ }^{\circ} \mathrm{C}$ & $\begin{array}{l}1.2-1.4 \mathrm{~W} / \\
\mathrm{mK}\end{array}$ \\
\hline Basalt & $\begin{array}{l}\text { Stable up to } 800^{\circ} \mathrm{C} \text {, without } \\
\text { phase changes }\end{array}$ & $6.4 \times 10^{-6} /{ }^{\circ} \mathrm{C}$ & $1.7 \mathrm{~W} / \mathrm{mK}$ \\
\hline
\end{tabular}

$\left(\mathrm{AH}_{3}\right)$. The two first compounds are chemically unstable and suffer a conversion to the more stable compounds $\mathrm{C}_{3} \mathrm{AH}_{6}$ and $\mathrm{AH}_{3}$. This conversion could take years at ambient temperature, but it can finish within days at $40{ }^{\circ} \mathrm{C}$ and within hours at $70{ }^{\circ} \mathrm{C}$ [17]. This conversion produces an irreversible strength loss and an increase of porosity, and it stabilizes in the new conditions. Regarding its behavior at high temperatures, Calcium Aluminate Hydrates $\mathrm{CAH}_{10}, \mathrm{C}_{2} \mathrm{AH}_{8}$, and $\mathrm{C}_{3} \mathrm{AH}_{6}$ dehydrate at temperatures of $120^{\circ} \mathrm{C}, 170-195^{\circ} \mathrm{C}$, and $240-370{ }^{\circ} \mathrm{C}$, respectively [18]. Aluminum Hydroxide, $\mathrm{AH}_{3}$, dehydrate between 210 and $300{ }^{\circ} \mathrm{C}$ and the gel compounds start their decomposition at $100{ }^{\circ} \mathrm{C}$. At $400{ }^{\circ} \mathrm{C}$, all the compounds are completely dehydrated. This dehydration is more stable than in OPC after cooling [14], reducing the swelling risk and therefore resulting in expected higher performance requirements at high temperatures and during cycling.

Since aggregates usually comprise around $70 \%$ of the volume of concrete, their response when exposed at high temperatures is critical. Siliceous, calcareous, and basalt aggregates are the most common aggregates for concrete with known properties at high temperatures [14]. These properties are summarized in Table 1 . The desired properties of the aggregates to be used in refractory applications are stability and long-term performance at high temperatures and low thermal expansion, the latter being the main responsible for microcracking during thermal fatigue processes. The optimum thermal conductivity of the material will depend on its application. In the case of concrete used for insulation, low thermal conductivity is required to minimize the increase of temperature within the material. On the other hand, for concrete used as a thermal energy storage material, a balance between high thermal conductivity and low thermal losses is mandatory. The higher the thermal conductivity, the faster the thermal energy is stored since the heat is exchanged more efficiently. Nevertheless, high values of thermal conductivity imply low heat capacity because the heat might be lost to the surroundings faster. For that reason, a balance between the two parameters is essential for thermal energy storage applications. The thermal conductivity values that can be obtained in concrete when using conventional types of aggregates are also included in Table 1 [19]. Other special aggregates have been proposed for different purposes in refractory applications, such as lightweight aggregates to achieve insulating properties [20,21] or alumina-based aggregates [22,23].

Several studies have been published on the physical and mechanical properties of concrete with siliceous or calcareous aggregates after suffering high temperatures. At $90{ }^{\circ} \mathrm{C}$, compressive strength can decrease to $75-80 \%$ of its initial value, due to the stresses at the interface aggregate-paste $[14,19]$. Between 90 and $200{ }^{\circ} \mathrm{C}$, compressive strength remains constant or even increases slightly $[14,19]$. Temperatures over $200{ }^{\circ} \mathrm{C}$, however, result in drastic reductions in compressive strength, up to $20-40 \%$ of its initial value at $600{ }^{\circ} \mathrm{C}$, depending on the aggregate type, size, and concrete composition [19]. Other properties, such as tensile strength, modulus of elasticity, and bond strength, have also been reported to experience similar trends [24,25]. Regarding thermal properties, thermal conductivity generally decreases with the

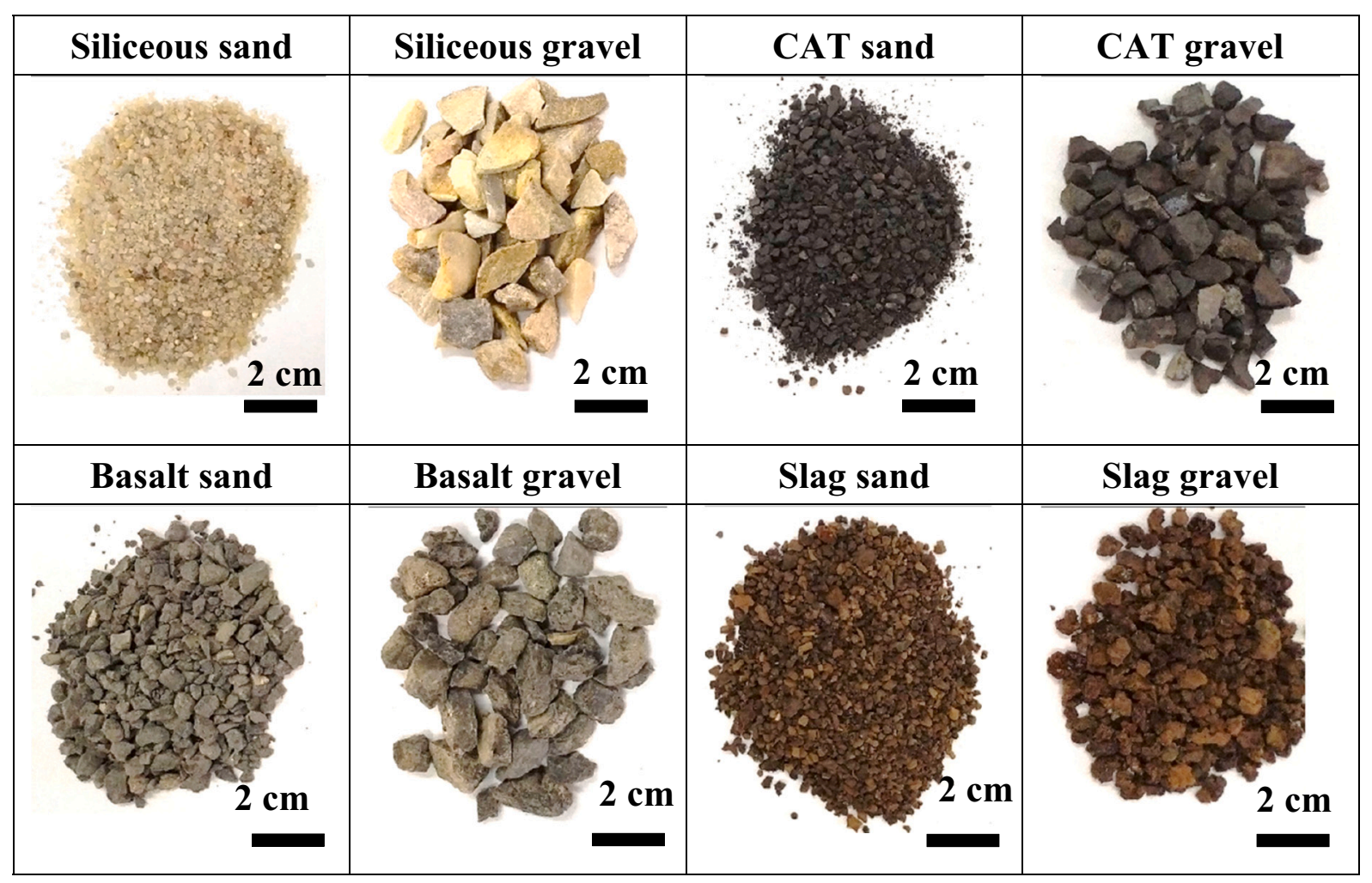

Fig. 1. Aggregates used in the concrete mixes. 


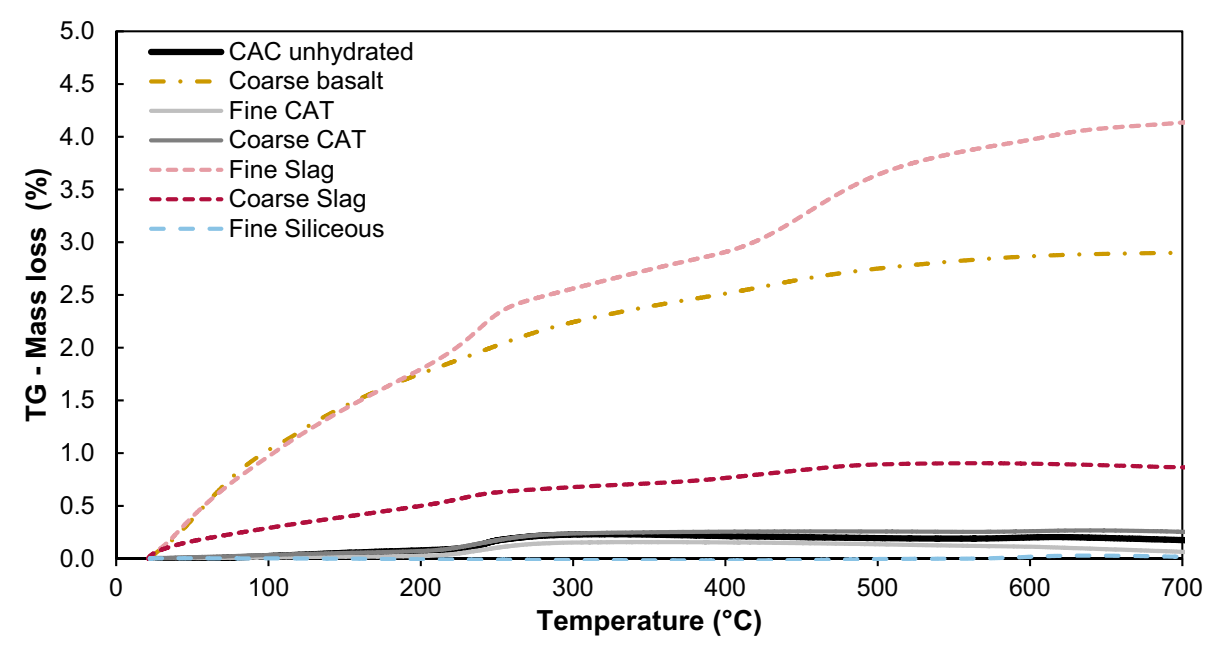

Fig. 2. Mass loss obtained by TG for CAC, siliceous, basalt, CAT, and Slag aggregates.

temperature up to $500{ }^{\circ} \mathrm{C}[19,23,26,27]$, but some studies reported a slight increase afterward, and after the first heating [23]. On the contrary, heat capacity generally increases at higher temperatures $[19,26]$.

In the case of TES, the reductions in mechanical properties can be even further accelerated due to the thermal cycles produced during the charge/discharge processes, since hysteresis effects and increased residual expansions take place [14]. Only a few studies have been performed on concrete under thermal cycles conditions. John et al. [5] exposed OPC concrete with limestone (calcareous), sandstone (siliceous), and syenite aggregates (similar to granite) to 30 thermal cycles between 300 and $600{ }^{\circ} \mathrm{C}$. Their results showed that the average final compressive strength values resulted in approximately $30 \%$ of their initial value, contrasting with the strength losses reported after constant temperature conditions. Alonso et al. [7] studied the changes induced by dehydration and consecutive heat/cool cycles $\left(290-550{ }^{\circ} \mathrm{C}\right)$ in concrete at the micro- and macro-level using CAC blended with blast furnace slag (BFS), and comparing silico-calcareous aggregates with aggregates from industrial waste slag from ore processing. Their experiments show decays in compressive strength up to $50 \%$ after the first thermal cycle. Their results showed that concrete based on blended CAC with appropriate design could be employed for TES up to $550{ }^{\circ} \mathrm{C}$ in solar thermal energy plants.

This work aims at analyzing the thermo-mechanical properties of concrete with three types of aggregates, including several aggregates combinations, after being exposed to thermal cycles. The results have been divided into two parts to detect trends in the loss and stabilization of properties. The first part analyses the effect of dehydration on physical and mechanical properties of concrete after the first thermal cycle. Dehydration is hypothesized to produce most of the reductions in performance, but there are no publications detailing results after the first thermal cycle. Afterward, the second part analyses the losses produced during subsequent thermal cycles, which would represent the thermal fatigue stage under service conditions. Additionally, the thermal parameters of the studied concretes are analyzed experimentally at residual conditions due to their importance for certain types of concrete structures. The complete thermo-mechanical evaluation aims to quantify the effect of the thermal cycles on the material itself and to support the prediction of its long-term response.

\section{Experimental procedure}

\subsection{Materials}

\subsubsection{Aggregates}

This study focuses on three types of aggregates with potential good behavior at high temperatures: i) crushed basalt aggregates from Pedrera Can Saboia (Spain), with density $2.76 \mathrm{ton} / \mathrm{m}^{3}$; ii) calcium aluminate aggregates, a synthetic clinker aggregate based on CAC cement

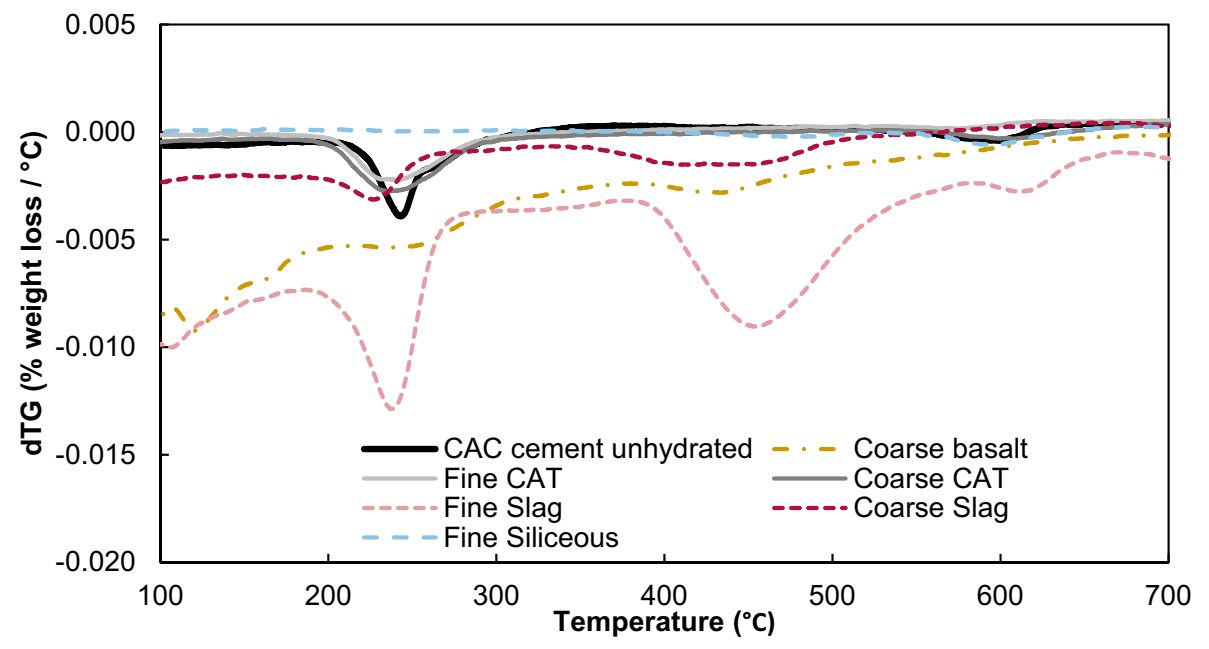

Fig. 3. dTG curves obtained by TG for CAC, siliceous, basalt, CAT, and Slag aggregates. 
Table 2

Oxide content of CAC cement (wt $\%)$.

\begin{tabular}{lllllllll}
\hline & $\mathrm{Al}_{2} \mathrm{O}_{3}$ & $\mathrm{CaO}$ & $\mathrm{Fe}_{2} \mathrm{O}_{3}$ & $\mathrm{SiO}_{2}$ & $\mathrm{MgO}$ & $\mathrm{Na}_{2} \mathrm{O}$ & $\mathrm{K}_{2} \mathrm{O}$ & $\mathrm{SO}_{3}$ \\
\hline $\mathrm{CAC}$ & 40.3 & 37.43 & 15.2 & 4.4 & 0.47 & 0.16 & 0.14 & 0.06 \\
\hline
\end{tabular}

produced by Cement Molins with density $3.10 \mathrm{ton} / \mathrm{m}^{3}$; and iii) a waste slag of high density and with high contents of iron salts of high crystalline structure and without hydraulic properties, originated in old sulfur and copper mines, São Domingos mine (Portugal), with density ranging between 3.50 and 3.70 ton $/ \mathrm{m}^{3}$. Additionally, conventional siliceous aggregates were used as a reference. Fig. 1 shows pictures of all the aggregates used in this work.

Due to the relevance of the stability of the aggregates at high temperatures, thermogravimetric analysis (TG) and differential thermogravimetric analysis (dTG) were performed. TG evaluates the mass loss of each aggregate, and the presence of peaks in the dTG curves indicates reactions or phase transformations.

The mass losses from TG results are displayed in Fig. 2 showing good stability with losses below $4 \%$ depending on the aggregate. Basalt aggregates experienced small mass losses that were stabilized after $500^{\circ} \mathrm{C}$. CAT aggregates were completely stable at high temperature, with very similar results to unhydrated CAC cement, and negligible mass losses. São Domingos fine Slag aggregates experienced significant mass loss, being higher than the other aggregates in all temperature ranges analyzed, which are thought to be produced by the small calcite and iron oxides content of these Slags. São Domingos coarse Slag aggregates experienced lower weight loss in than the fine aggregate.

Fig. 3 shows the dTG curves obtained for the temperature range of $100-700{ }^{\circ} \mathrm{C}$. Basalt aggregates experienced several transformations up to $450{ }^{\circ} \mathrm{C}$. CAT and CAC dTG curves show low energy transformations around $240{ }^{\circ} \mathrm{C}$, which can be associated with the transformation of $\mathrm{AH}_{3}$ $[28,29]$, indicating marginal hydration of the cement. Regarding the São Domingos fine Slag aggregates, the results display several transformations, at $230{ }^{\circ} \mathrm{C}$ and $440{ }^{\circ} \mathrm{C}$ associated with the iron-silica compounds, which comprise the majority of their composition, and at $670{ }^{\circ} \mathrm{C}-730{ }^{\circ} \mathrm{C}$ due to the decomposition of carbonated phases and calcite $[30,31]$. The curves related to São Domingos coarse Slag aggregates are more similar to that of coarse basalt aggregates but experienced lower mass losses.

\subsubsection{Concrete mixes}

Four concrete types were prepared using Calcium Aluminate Cement (CAC) from Cement Molins (composition in Table 3) and the aggregates mentioned above. The water/cement ratio used was 0.43 . Lignosulphonate-based plasticizer (Sikament 165) was added, in a dosage of $1 \mathrm{~kg} / \mathrm{m}^{3}$, to maintain high workability [32]. The high cement
Table 4

Overview of the specimens analyzed in this work.

\begin{tabular}{|c|c|c|c|}
\hline Shape & Dimension & Tests performed & No. of specimens tested \\
\hline Cylinder & $\begin{array}{l}\Phi 75 \mathrm{~mm} \\
150 \mathrm{~mm} \\
\text { height }\end{array}$ & $\begin{array}{l}\text { - Mass loss } \\
\text { - Compressive } \\
\text { strength }\end{array}$ & $\begin{array}{l}2 \text { per cycle }(0,1,6,10)=8 \text { / } \\
\text { concrete type } \\
+25,75 \text { cycles for a selected } \\
\text { mix }\end{array}$ \\
\hline Cylinder & $\begin{array}{l}\Phi 75 \mathrm{~mm} \\
150 \mathrm{~mm} \\
\text { height }\end{array}$ & - Temperature control & 1 per mix \\
\hline Disks & $\begin{array}{l}\Phi 75 \mathrm{~mm} \\
17 \mathrm{~mm} \\
\text { height }\end{array}$ & $\begin{array}{l}\text { - Mass loss } \\
\text { - Thermal parameters } \\
\text { - Microcracking } \\
\text { - Samples for } \\
\text { porosity/SEM }\end{array}$ & $\begin{array}{l}2 \text { per cycle }(0,1,6,10)=8 \text { / } \\
\text { concrete type } \\
+25,75 \text { cycles for a selected } \\
\text { mix }\end{array}$ \\
\hline
\end{tabular}

content used in the concrete composition also promoted higher workability, which is a typical solution when using CAC cement [33]. Table 2 shows the composition of the CAC cement used in this study.

The aggregates combinations used in the four concrete mixes studied are: 1) a mix with coarse and fine aggregates (named CAT); 2) a mix of coarse basalt aggregate and fine CAT aggregate (Basalt-CAT); 3) a ternary mix combining basalt gravel, CAT sand with 15\% of aggregate substitution by São Domingos Slag gravel and sand (Basalt-CAT-Slag $15 \%)$; and 4) a ternary mix combining basalt gravel, CAT sand with $30 \%$ of aggregate substitution by São Domingos Slag gravel and sand (BasaltCAT-Slag 30\%). Higher substitution rates were not investigated due to the tendency of the Slag to produce segregation because of their high density and low fines content. Additionally, a mix with only siliceous aggregates (Siliceous) was tested as a reference to compare the mechanical and thermal conductivity changes. These mixes have the same volume of paste and aggregates to guarantee the comparability of the results.

Table 3 shows the composition of the mix designs as well as their slump and compressive strength values obtained as per EN 12350-2 and EN 12390-3:2009, respectively. Compressive strength was tested in cylinders of $75 \mathrm{~mm}$ of diameter and $150 \mathrm{~mm}$ high since this size has been reported as adequate to evaluate concrete strength testing when the maximum size of the aggregate used does not exceed $25 \mathrm{~mm}$ [34].

Polypropylene (PP) short fibers (12 mm length, $\sim 18 \mu \mathrm{m}$ diameter) were added to all the mixes as a contingency to avoid spalling during the tests at high temperatures. These fibers melt when the temperature reaches $165^{\circ} \mathrm{C}$ and vaporize at $350^{\circ} \mathrm{C}$, creating voids that are thought to support in relieving internal stresses $[35,36]$ produced by the internal steam movements at high temperatures.

All specimens cured inside the molds for one day; after that, they cured in a humidity chamber at $95 \%$ relative humidity and $20^{\circ} \mathrm{C}$ until their testing time. After the curing stage, some of the cylindrical

Table 3

Concrete mix proportions, slump, and compressive strength results.

\begin{tabular}{|c|c|c|c|c|c|}
\hline & CAT & Basalt-CAT & Basalt-CAT-Slag 15\% & Basalt-CAT-Slag 30\% & Siliceous \\
\hline Cement CAC $\left(\mathrm{kg} / \mathrm{m}^{3}\right)$ & 600 & 600 & 600 & 600 & 600 \\
\hline Water $\left(\mathrm{kg} / \mathrm{m}^{3}\right)$ & 258 & 258 & 258 & 258 & 258 \\
\hline Gravel 1 - Siliceous 4-12 mm $\left(\mathrm{kg} / \mathrm{m}^{3}\right)$ & 0 & 0 & 0 & 0 & 742 \\
\hline Gravel 2 - Basalt 4-12.5 mm (kg/m $\left.\mathrm{m}^{3}\right)$ & 0 & 788 & 682 & 576 & 0 \\
\hline Gravel 3 - CAT 3-10 mm $\left(\mathrm{kg} / \mathrm{m}^{3}\right)$ & 885 & 0 & 0 & 0 & 0 \\
\hline Gravel 4 - Slag $1-6.3 \mathrm{~mm}\left(\mathrm{~kg} / \mathrm{m}^{3}\right)$ & 0 & 0 & 139 & 278 & 0 \\
\hline Sand 1 - Siliceous $0-3 \mathrm{~mm}\left(\mathrm{~kg} / \mathrm{m}^{3}\right)$ & 0 & 0 & 0 & 0 & 693 \\
\hline Sand 2 - CAT $0.25-4 \mathrm{~mm}\left(\mathrm{~kg} / \mathrm{m}^{3}\right)$ & 826 & 826 & 714 & 602 & 0 \\
\hline Sand 3 - Slag $0.25-2 \mathrm{~mm}\left(\mathrm{~kg} / \mathrm{m}^{3}\right)$ & 0 & 0 & 128 & 256 & 0 \\
\hline Polypropilene fibers $\left(\mathrm{kg} / \mathrm{m}^{3}\right)$ & 2 & 2 & 2 & 2 & 2 \\
\hline Plasticizer sikament 165 & 1 & 1 & 1 & 1 & 1 \\
\hline Water/cement $(w / c)$ & 0.43 & 0.43 & 0.43 & 0.43 & 0.43 \\
\hline Slump (cm) & 22 & 17 & 17 & 15 & - \\
\hline Compressive strength at $7 \mathrm{~d}(\mathrm{MPa})$ & 52.08 & 52.45 & 50.6 & 50.28 & 57.65 \\
\hline Compressive strength at $28 \mathrm{~d}(\mathrm{MPa})$ & 66.41 & 59.81 & 53.48 & 58.30 & - \\
\hline
\end{tabular}




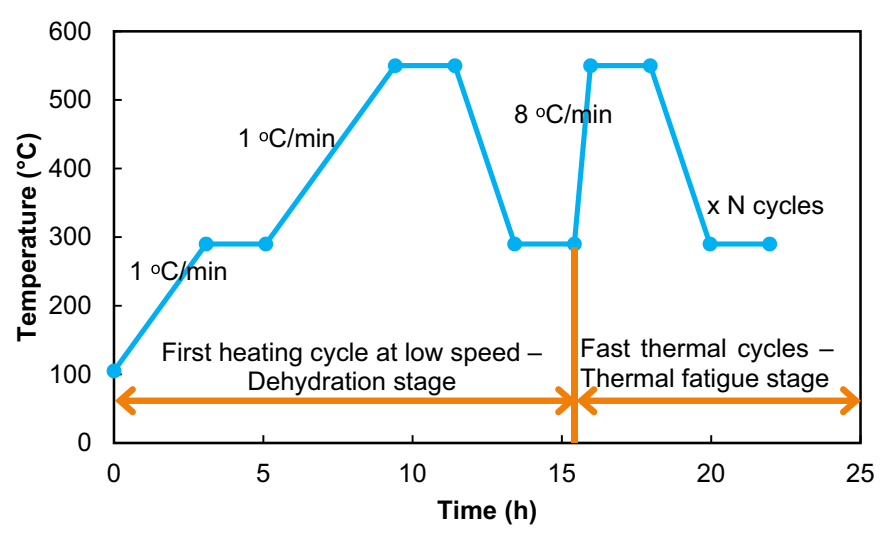

Fig. 4. Thermal cycles used for the first slow cycle (dehydration) and the fast cycles (fatigue).

specimens were cut in disks of approximate width of 17-18 mm. After cutting the disks, their surface was cleaned with water to remove the wet dust attached to the surface. Then, the disks were stored again in the humidity chamber until the age of seven days with the other samples, since the acquisition of strength of CAC mixes is minor after seven days $[7,37]$.

\subsection{Methodology}

Table 4 shows a summary of the tests performed in this work. Concrete cylinders were used for the evaluation of mass and compressive strength before and after 1, 6, and 10 thermal cycles. Two cylinders were used for each measure. Concrete disks were used to measure: thermal conductivity, Mercury Intrusion Porosimetry, and image analysis of microcracking. Microstructural changes were analyzed through Scanning Electron Microscopy (SEM) before and after the thermal cycles.

Regarding the microcracking study, an optical microscope Nikon SMZ-2 $\mathrm{T}$ with a camera was used for taking the photos. Two magnifications were used: a) one covering an area of $14.43 \mathrm{~mm} \times 11.25 \mathrm{~mm}$ for the definition of the pattern and crack area, and b) another covering an area of $4.81 \mathrm{~mm} \times 3.75 \mathrm{~mm}$ for a better measure of the crack width. The evolution of crack width and crack area were analyzed using the photography software GIMP by counting pixels forming the cracks.

Thermal conductivity was measured at room temperature using the Quick Thermal Conductivity Meter QTM-700 from KEM, Kyoto Electronics Manufacturing. Additionally, thermal conductivity, heat capacity, and diffusivity were evaluated at room temperature using the ISOMET model 2104 (Applied Precision). In both cases, the devices use the physic principle of the hot wire method. Several specimens were tested with the two devices, showing equivalent thermal conductivity results.

\subsubsection{Preconditioning}

Before performing the thermal cycles, all the concrete specimens were dried inside an oven at $105^{\circ} \mathrm{C}$ for three days. Mass variation was evaluated several times after being introduced in the oven. The results showed that most of the water evaporation was produced during the first $24 \mathrm{~h}$ in the cylindrical specimens, demonstrating that three days of drying are enough for the reduction of the initial free water content for these types of concrete and specimen size.

\subsubsection{Thermal cycles regime}

Fig. 4 shows the thermal cycle defined for the experimental work, with a heating rate of $1{ }^{\circ} \mathrm{C} / \mathrm{min}$ for the dehydration stage and $8{ }^{\circ} \mathrm{C} / \mathrm{min}$ for the thermal fatigue stage. In TES and HTF systems, heating rates can be adapted to some extent to the material since its purpose is to be used under service conditions. The first heating rate can be limited to slow rates to reduce concrete spalling risk, which is higher during the first heating because of the high thermal gradients between the external heated surface and the core of the element and the water pressures generated during the water vapor release. Once the cement paste has been dehydrated, this risk is significantly reduced, and the following heating cycles for simulating the thermal fatigue stage can be produced at a higher rate, simulating the real operating conditions of heat charge/ discharge.

One cylindrical specimen for each concrete type was used to control the real temperature reached in the interior of the specimen in its geometric gravity center (distance from the surface $37.5 \mathrm{~mm}$ ) during the thermal cycles by using an embedded thermocouple type K. The thermal inertia of the material produced a delay in the temperature profile of 30 min during the dehydration cycle and of almost one hour during the thermal fatigue stage. Despite this delay, all the mixes ultimately underwent the designed thermal cycles, demonstrating the suitability of the selected heating rates for evaluating these concrete mixes and sample sizes for the study.

A SATER oven, able to control the heating rates, was used for performing the thermal cycles. The oven has two electric resistances located in the lateral surfaces, as shown in Fig. 5. Fig. 5 shows the geometrical disposition of specimens inside the oven, their relative position to the electric resistances, and the heat flow direction. This symmetrical disposition of specimens was decided to ensure that all the specimens experienced the same heat exposure. The central specimen, with the embedded thermocouple, controlled the temperature profile reached in the interior of the material. After $\mathrm{N}$ thermal cycles, the specimens were

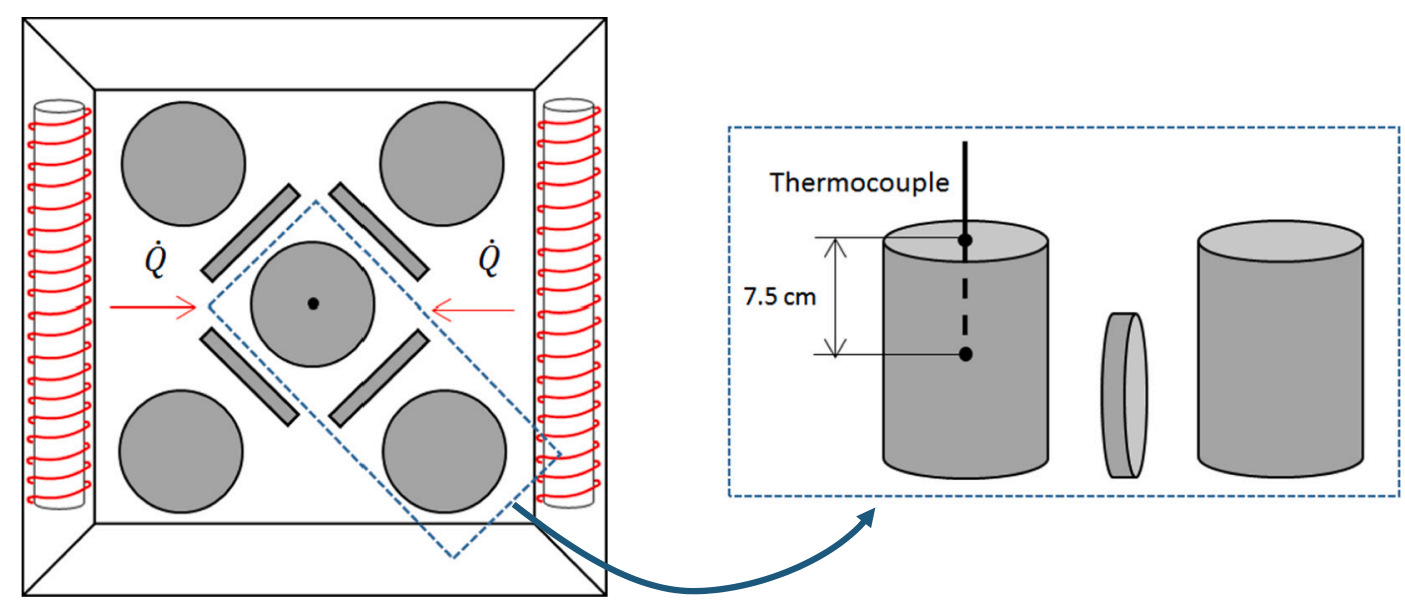

Fig. 5. Position of the concrete cylinders and disks inside the oven (left) and detail (right). 


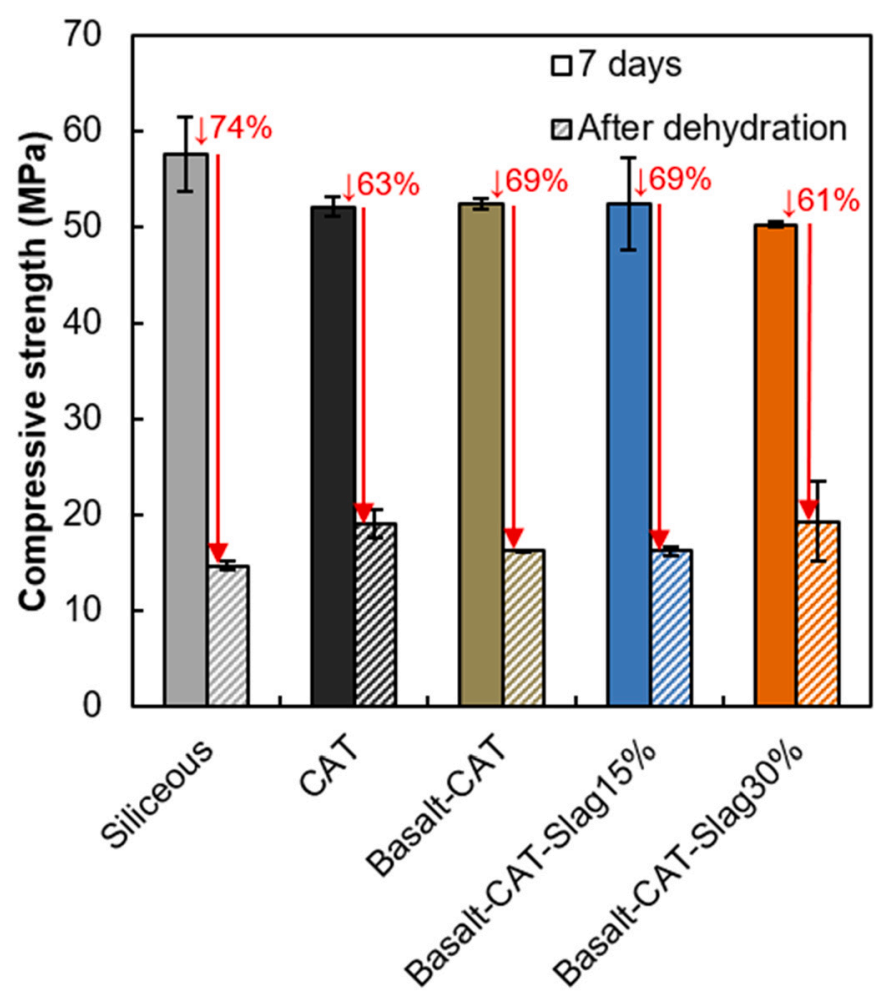

Fig. 6. Compressive strength losses after the first thermal cycle: average and standard deviation values. cooled down to room temperature inside the furnace without evacuating heat promptly, in order to avoid inducing high thermal gradients into the material. After that, the specimens were stored in a desiccator before the scheduled tests.

\section{Results and discussion}

\subsection{Dehydration stage}

\subsubsection{Loss of physical properties}

Mass variation was obtained for each concrete type after the first slow cycle performed between 290 and $550{ }^{\circ} \mathrm{C}$. Mass variation was expressed as a percentage of the dry mass of the sample (the mass measured after drying for three days). In all concretes analyzed, the mass loss obtained was around 5 and $6 \%$.

Similarly, compressive strength was evaluated type after the first slow cycle, and the values obtained are displayed in Fig. 6 . and all the mixes experienced a significant compressive strength loss, with values between 26 and 39\% of their initial strength (that is, strength losses of 61-74\%). From all the studied mixes, concrete with siliceous aggregates experienced the harshest decrease in strength, showing their lower suitability for high-temperature applications compared to the other more stable thermal aggregates analyzed.

The primary cause for the loss of mechanical properties produced during the first cycle is related to the decomposition of the CAC cement paste due to dehydration and release of chemically bound water in the hydrated compounds $\mathrm{CAH}_{10}, \mathrm{C}_{2} \mathrm{AH}_{8}, \mathrm{C}_{3} \mathrm{AH}_{6}$, and $\mathrm{AH}_{3}$. The dehydration process of CAC cement paste is completed at $400{ }^{\circ} \mathrm{C}$ [18].

The results of mass loss obtained are slightly lower than the values reported in the literature using OPC concrete with silico-calcareous
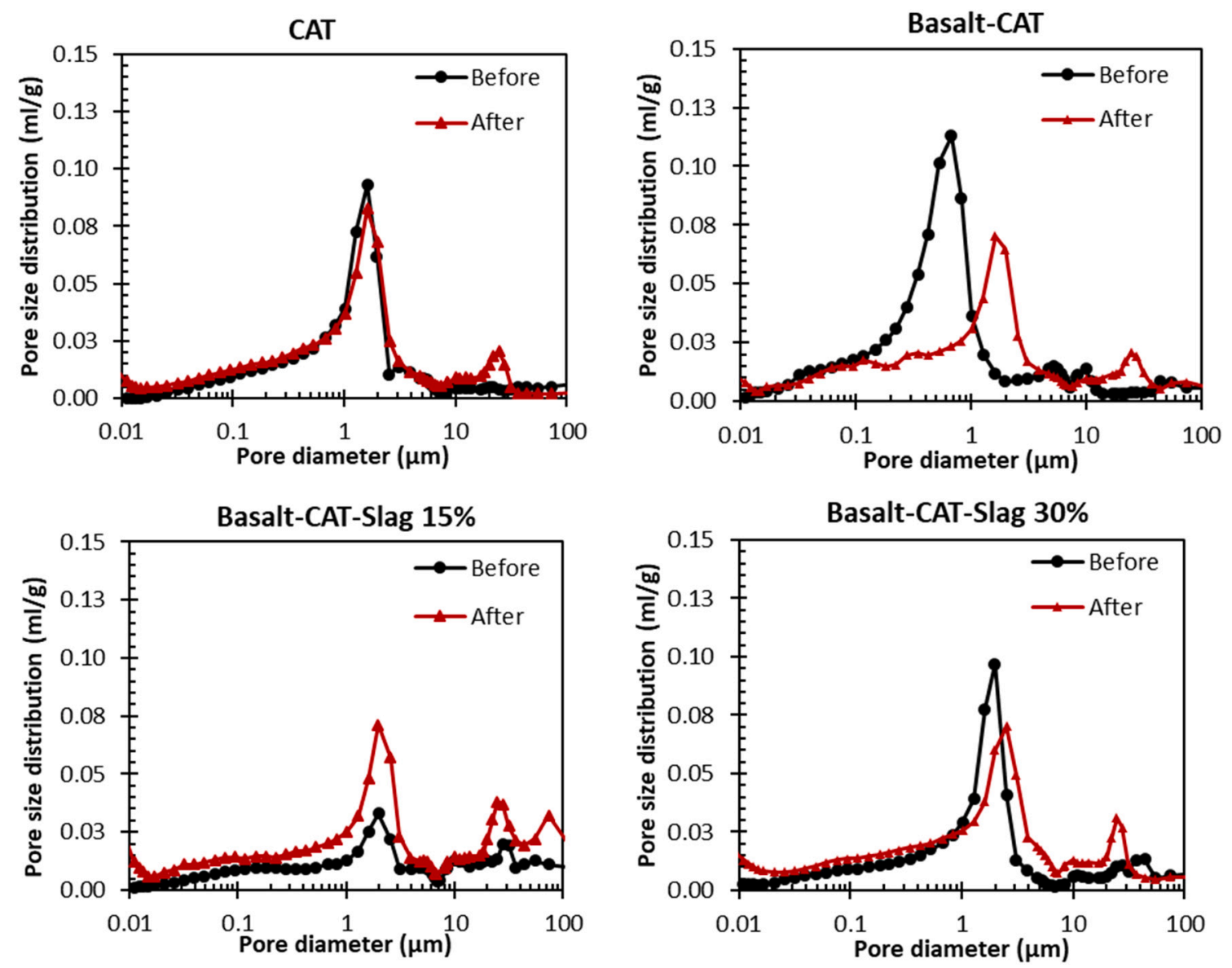

Fig. 7. Pore size distribution for the four concrete mixes before and after thermal cycling. 

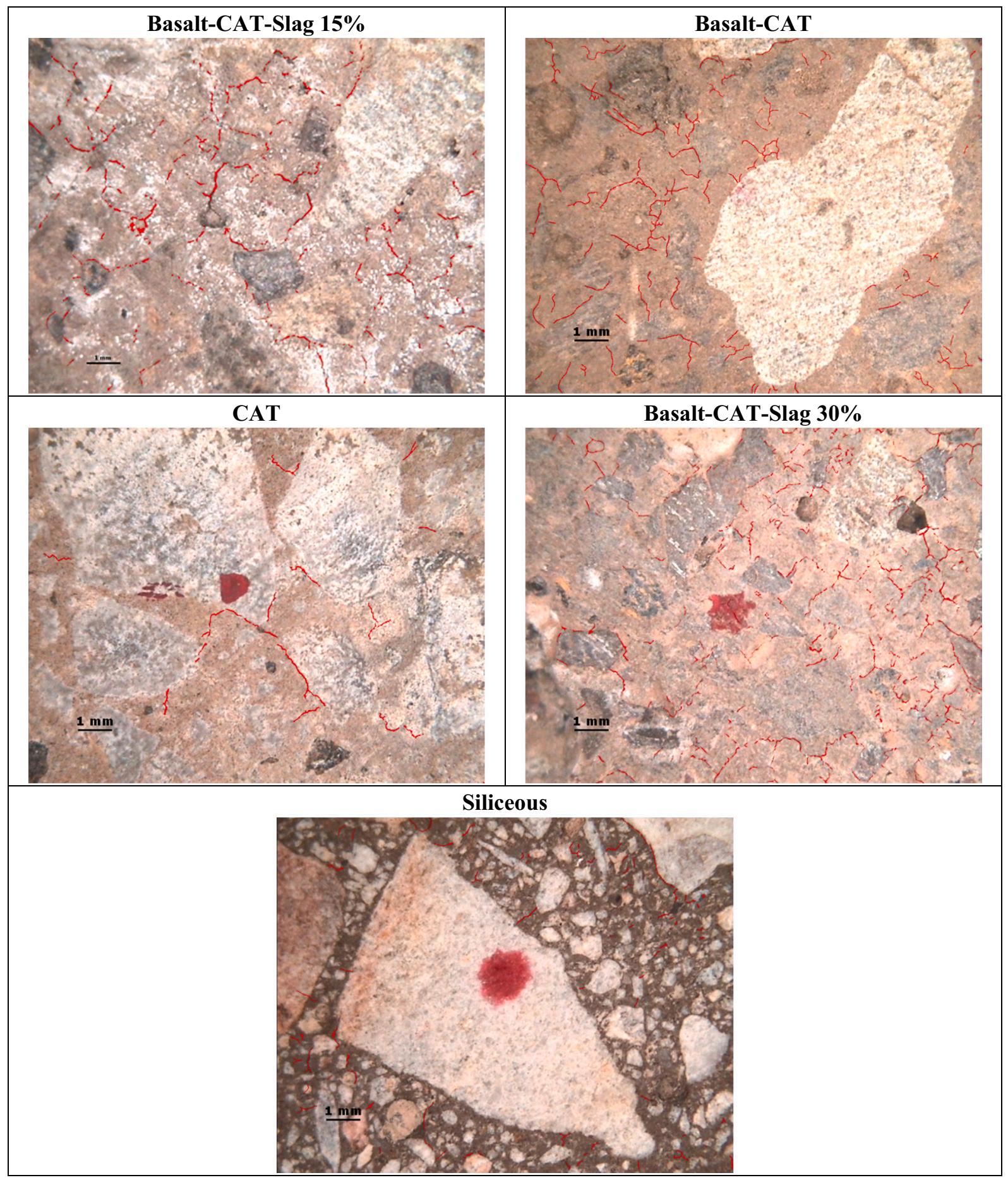

Fig. 8. Random cracking patterns produced after the first thermal cycle in each mix.

aggregates, where the mass losses after reaching $600{ }^{\circ} \mathrm{C}$ can range between 5 and $10 \%[25,26]$, and are in the same order of magnitude as others registered with OPC [38]. The results of compressive strength losses are coherent with those published in the literature $[7,14]$. Compressive strength losses of around $40 \%$ were reported for conventional aggregates after being exposed to temperatures of $500{ }^{\circ} \mathrm{C}$ (either siliceous or calcareous). On the contrary, aggregates with stable behavior at high temperatures (such as magnetite or serpentine aggregates) may lose only $30 \%$ of the initial strength after being exposed to $500{ }^{\circ} \mathrm{C}[14,38]$. These results highlight the importance of using temperature stable aggregates since the operating range of molten salts as heat transfer fluid is close to the temperatures of transformations in the case of siliceous aggregates and of the decarbonation in the case of calcium carbonate.

\subsubsection{Pore volume changes}

Mercury Intrusion Porosimetry (MIP) tests were used to characterize the pore size distribution of all the concrete mixes, before and after thermal cycling. The results are displayed in Fig. 7. Before the thermal cycles, most of the pores are capillary pores, with sizes around 1.6-2 $\mu \mathrm{m}$ (CAT, Basalt-CAT-Slag 15\%, and Basalt-CAT-Slag 30\%), while BasaltCAT has a slightly finer pore distribution (pores around $0.7 \mu \mathrm{m}$ ). 


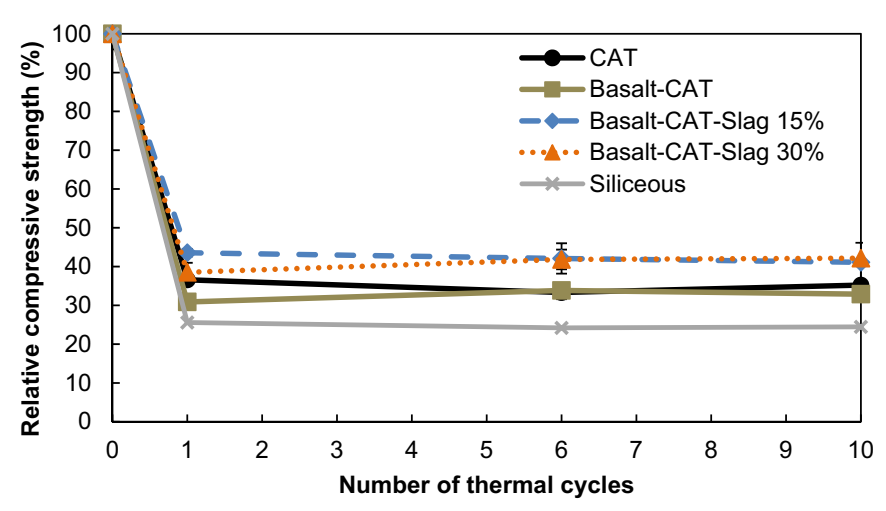

Fig. 9. Residual compressive strength variation of the concrete mixes after 1, 6, and 10 cycles: average and standard deviation values.

Three mixes have a secondary peak of porosity produced in the range of 10-25 $\mu \mathrm{m}$, associated with micropores. Conversely, CAT mix (only with CAT aggregates) showed no initial pores in that secondary region.

After thermal cycling, a new peak of porosity in the range of 24-27 $\mu \mathrm{m}$ size was found in all the concrete mixes, including the mix CAT. This range can be related to the presence of cracks (the size of the cracks from the image analyses ranges from 10 to $70 \mu \mathrm{m}$ ) and the vaporization of the polypropylene fibers (12 $\mathrm{mm}$ length and $18 \mu \mathrm{m}$ diameter), as reported in the literature [19].

\subsubsection{Microcracking patterns}

The cracking pattern was evaluated in the geometrical center of the concrete disks. The results obtained after the first thermal cycle show random cracking patterns with most of the cracks located around the aggregates and between aggregates and pores. Cracking was analyzed in detail after fatigue cycles to evaluate the area covered by cracks and crack width. Fig. 8 shows the cracks in red after the first thermal cycle for each concrete mix.

\subsection{Thermal fatigue stage}

\subsubsection{Loss of physical properties}

Mass evolution was measured after 1, 6, and 10 thermal cycles. The mix with only CAT aggregates (CAT), the two ternary mixes (BasaltCAT-Slag 15\% and Basalt-CAT-Slag 30\%), and the siliceous mix experienced similar losses. In contrast, slightly higher mass losses were obtained for the binary mix (Basalt-CAT). The mass losses were stabilized after the first thermal cycle of the dehydration stage and remained around 5.5 and $6.5 \%$ after the thermal fatigue stage.

Fig. 9 shows the relative values of compressive strength obtained using as reference the values obtained at seven days. The dispersion obtained is displayed in the error bars. A severe strength loss was produced after the dehydration cycle (cycle $\mathrm{N}=1$ ), and slight or nondetectable decreases were produced during the cycles. The mix with siliceous aggregates experienced the highest drop in strength, already produced after the first cycle, maintaining only around $25 \%$ of its initial strength. The mixes that maintain the highest percentage of the initial strength are ternary mixes with Basalt coarse aggregates, CAT fine aggregates, and São Domingos Slag (Basalt-CAT-Slag 15\% and Basalt-CATSlag 30\%). The inclusion of the São Domingos Slag aggregate led to a slight improvement in the thermal fatigue stage. The compressive strength of the ternary mixes after 10 thermal cycles was around 20 $\mathrm{MPa}$, while the other mixes did not reach $20 \mathrm{MPa}$ after the cycles.

John et al. [5] reported residual strength values after performing thermal cycles between 300 and $600{ }^{\circ} \mathrm{C}$ of around $30 \%$ of the initial strength. Their study used siliceous, calcareous, and syenite aggregates. Those results are consistent compared with the siliceous aggregates used in this work. In this study, the mixes with basalt and CAT, only CAT

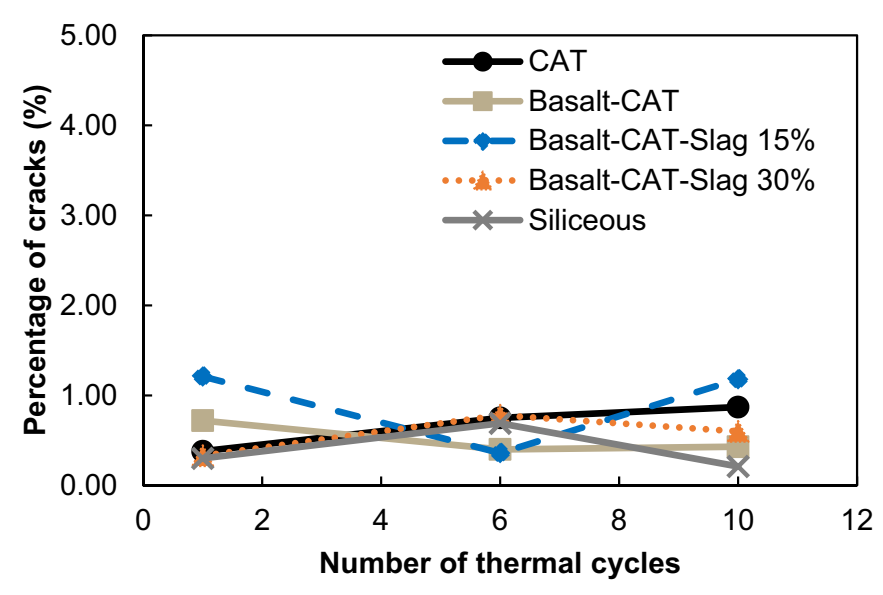

Fig. 10. Crack area variation of the four concrete mixes after 1,6 , and 10 cycles, measured in $\%$ of an area of $162.42 \mathrm{~mm}^{2}$.

aggregates, and especially, the ternary mixes, showed better retention of the mechanical properties, demonstrating their better thermal stability.

The Basalt-CAT-Slag15\% mix was selected to verify its long-term stability in terms of strength losses. The residual values of the compressive strength of the selected mix reached $38.3 \%$ of the initial strength after 25 cycles and $36.9 \%$ after 75 cycles. Thus, a decrease of around $5 \%$ of compressive strength took place between the tenth and the 75th cycles.

\subsubsection{Evaluation of the microcracking}

The percentage of microcracks was analyzed in the geometric center of the concrete sample. The results show a stabilization or slight increase in the percentage of microcracks in an area with the number of cycles (Fig. 10). The percentage of microcracks obtained was below $1.10 \%$ in all cases. It should be noted here that the specimens used for each picture are different, and then, the natural dispersion of the components in concrete produces different results in the cracking trends. Results found in the literature for concrete with calcareous, silicon, and silicocalcareous aggregates showed higher values of percentage of microcracks in the area for the silico-calcareous (5.44\%) and siliceous mixes (1.56\%) after heating at $600{ }^{\circ} \mathrm{C}$ [25]. Conversely, the calcareous mix had a $0.9 \%$ of microcracks, which is a similar value to those obtained in this study.

The percentage of cracks was analyzed at different distances between the border and the center of one of the cylindrical specimens after the thermal fatigue stage, as indicated in Fig. 11. The results obtained in these points are almost the same independently of the position analyzed (Fig. 12).

The maximum crack width was also quantified. In all cases, the maximum crack widths remained under $0.08 \mathrm{~mm}$, and generally below $0.05 \mathrm{~mm}$, which are usual crack sizes for service conditions in concrete. The ternary mixes had a wider maximum crack width $(0.08 \mathrm{~mm})$, especially the mix with $15 \%$ of São Domingos Slag. The mixes with the narrower maximum crack width were Basalt-CAT and CAT mixes, with maximum crack sizes below $0.025 \mathrm{~mm}$ and stabilized behavior after the fatigue cycles.

\subsubsection{Microstructure after thermal fatigue}

Cracks were detected concentrated in the aggregates' interface, caused by the expansion of the aggregates and shrinkage of the paste at high temperatures. Fig. 13 shows the cracks in the boundaries between the paste and the three types of aggregates after thermal cycles obtained by electronic microscopy. Cracks of constant size around $2 \mu \mathrm{m}$ were detected around basalt aggregates, which is the largest size of aggregate used in this work. CAT aggregates had very distributed and thin cracks in their boundary. São Domingos Slag aggregates also exhibited thin 


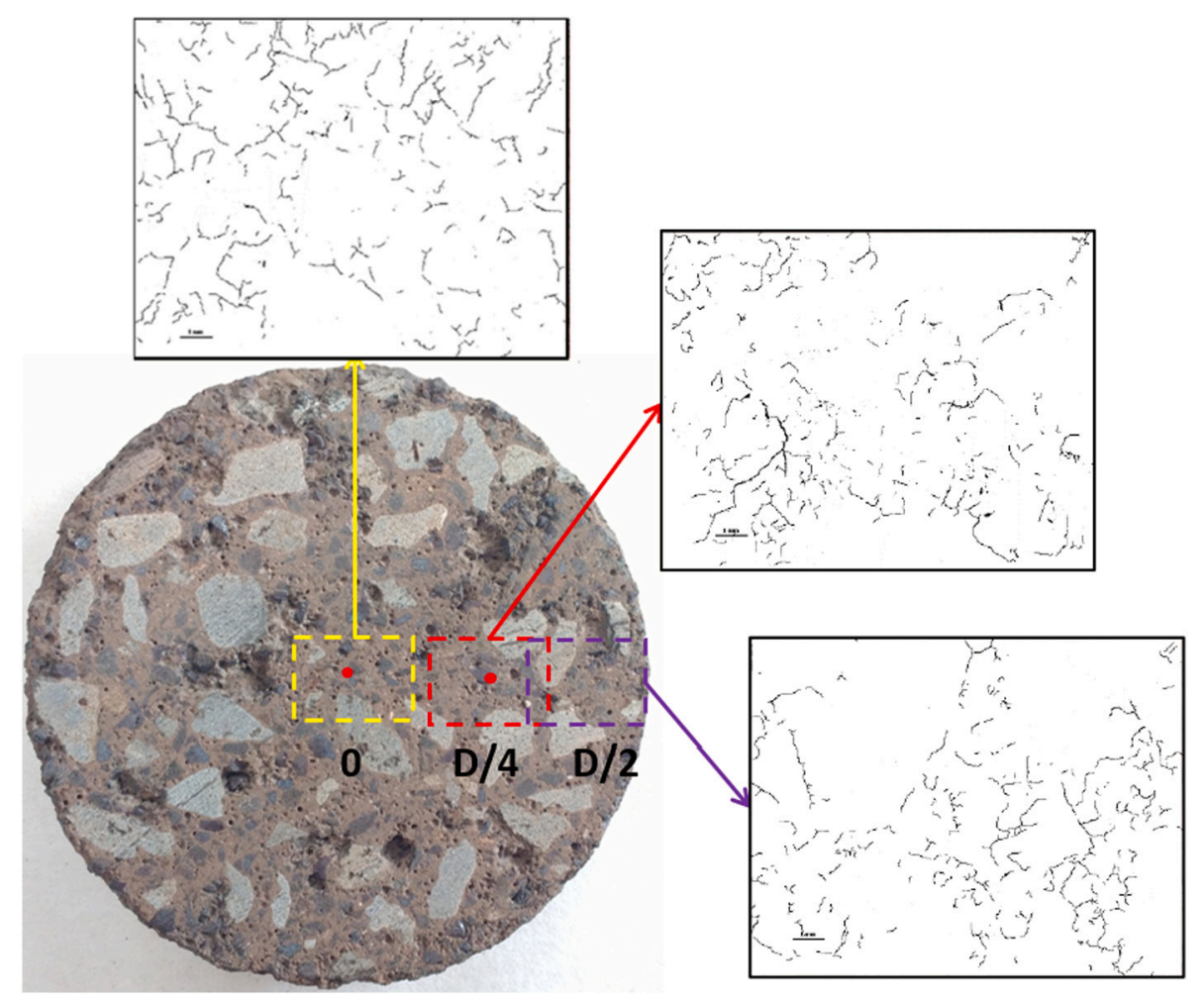

Fig. 11. Locations of the pictures taken in the cylindrical specimen.

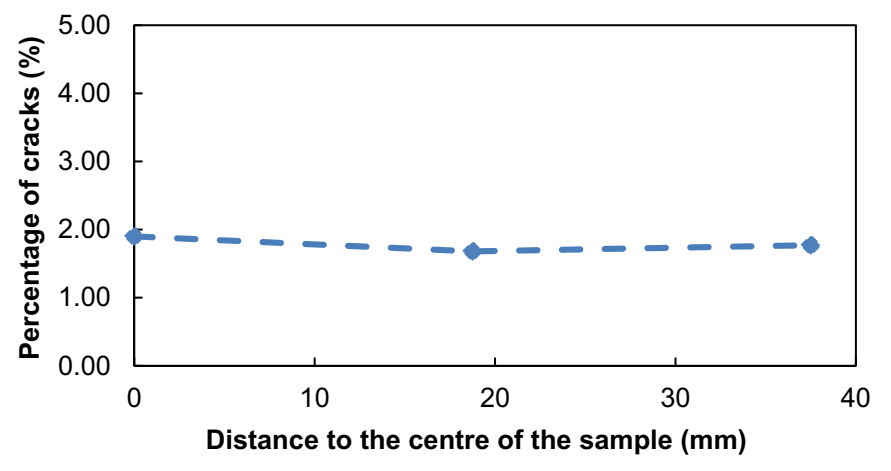

Fig. 12. Crack area percentage for Ba-C-S15 after thermal cycles for different locations.

cracks in their boundary, but they were wider than the cracks produced around CAT aggregates. The composition of the cement paste was analyzed in terms of oxide content at several points and showed no significant differences with the paste before the thermal cycles.

\subsubsection{Thermo-mechanical stability and long-term performance}

For the five concrete types studied in this work, the regression curve between compressive strength and the number of thermal cycles was calculated. Good fittings $\left(\mathrm{R}^{2}>0.90\right)$ were obtained following potential and logarithmic curves. The potential regression equations obtained through this method were used to estimate an extrapolation of the compressive strength to the long term. Considering that at the TES system each solar day implies one thermal cycle, after five years in service (1825 cycles), concrete strength is estimated to be $6.5 \mathrm{MPa}$ in the lowest case (siliceous aggregates mix) and $12.55 \mathrm{MPa}$ in the Basalt-CATSlag15\% mix. Similarly, after 25 years (9125 cycles), concrete strength is estimated as $5.25 \mathrm{MPa}$ in the siliceous aggregates mix, and $11 \mathrm{MPa}$ in the Basalt-CAT-Slag $15 \%$ mix. The results for the five mixes are displayed in Fig. 14. Comparing these values with the literature, another previous study made with CAC concretes exposed to 75 thermal cycles between 290 and $550^{\circ} \mathrm{C}$ obtained a compressive strength of $10 \mathrm{MPa}$ [7]. Another experiment with CAC concrete exposed to 30 thermal cycles between 300 and $600{ }^{\circ} \mathrm{C}$ obtained compressive strength values between 9 and 12 MPa [5]. One study reported an experimental compressive strength after being exposed to 2250 thermal cycles (lifetime of six years) of $15 \mathrm{MPa}$ [4]. All these results are consistent with the results of the five mixes analyzed in this paper.

\subsection{Evolution of thermal properties}

This section explains the experimental results obtained for thermal conductivity, volumetric heat capacity, and diffusivity after thermal cycles $(\mathrm{N}=0,1,6,10)$ measured at ambient temperature, that is, in residual conditions.

Concrete disks were exposed to the same thermal cycle showed in Fig. 4, and after $\mathrm{N}$ thermal cycles they were cooled to room temperature. The two points at 0 cycles represent the values obtained at the initial condition with moisture, and after being dried at $105{ }^{\circ} \mathrm{C}$ since the presence of humidity contributes to the thermal conductivity. The mix that obtained the higher thermal conductivity is the mix with siliceous aggregates. However, it is also the mix with the highest drop ( $50 \%$ of the initial conductivity in wet conditions). In comparison, the rest of the mixes followed the same trend with higher stability and with global decreases of only 30-35\% (see Fig. 15). Again, the critical loss of properties was produced during the dehydration stage (with decreases of around $18-30 \%$ ), whereas during the thermal fatigue stage, the decreases are less significant (7-12\%). The thermal conductivity values obtained when using the thermally stable aggregates before drying range between 1 and $1.3 \mathrm{~W} / \mathrm{mK}$. The values after the thermal cycles are, on average, $0.67 \mathrm{~W} / \mathrm{mK}$ for the Basalt-CAT mix, $0.76 \mathrm{~W} / \mathrm{mK}$ for the Basalt-CAT-S30 mix, $0.81 \mathrm{~W} / \mathrm{mK}$ for the Basalt-CAT-Slag $15 \%$ and 0.89 $\mathrm{W} / \mathrm{mK}$ for the CAT mix.

The evaporation of water in the pores and dehydration of the cement 


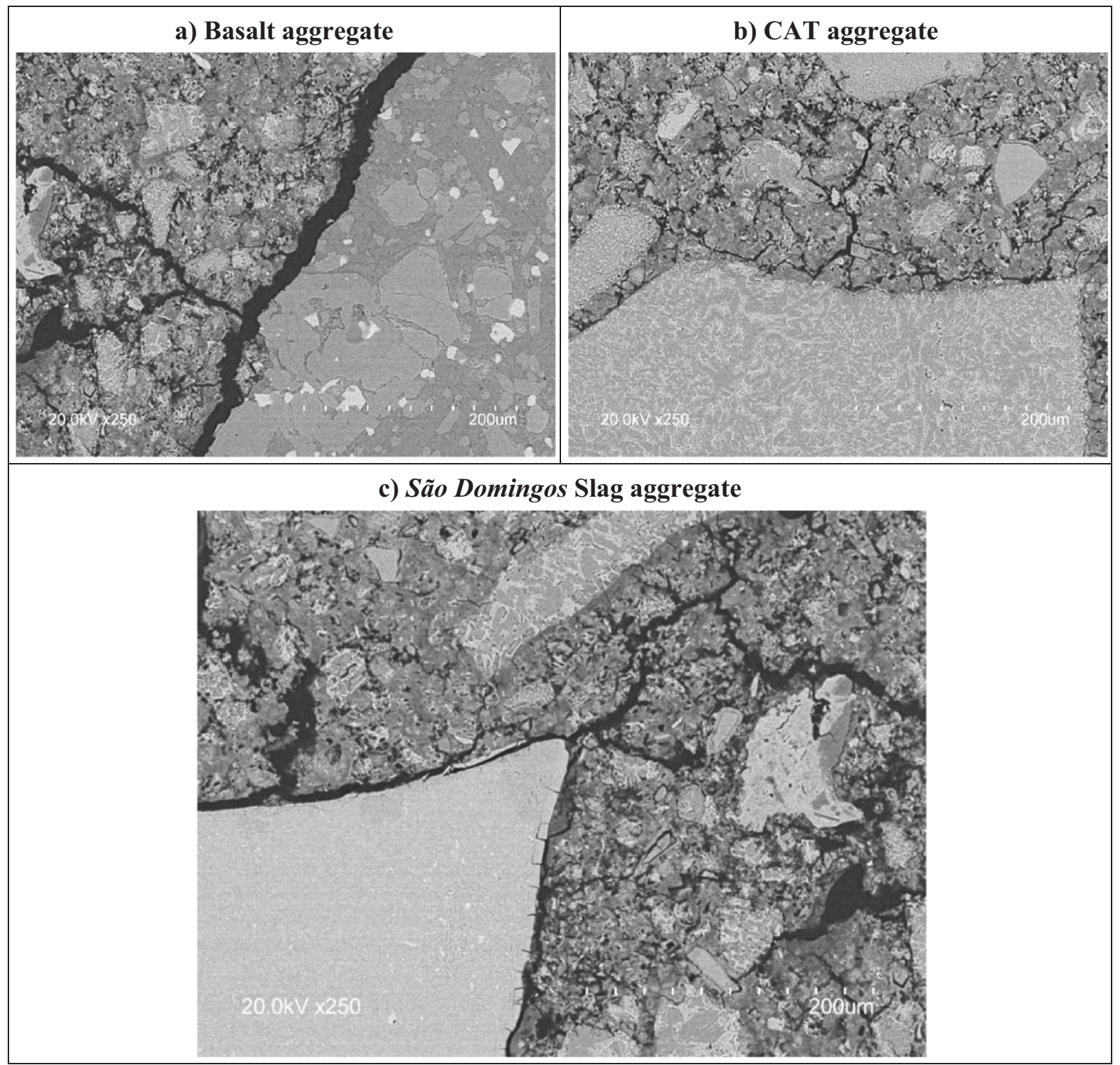

Fig. 13. Cracks produced in the interfaces between the cement paste and the three aggregates after thermal cycles.

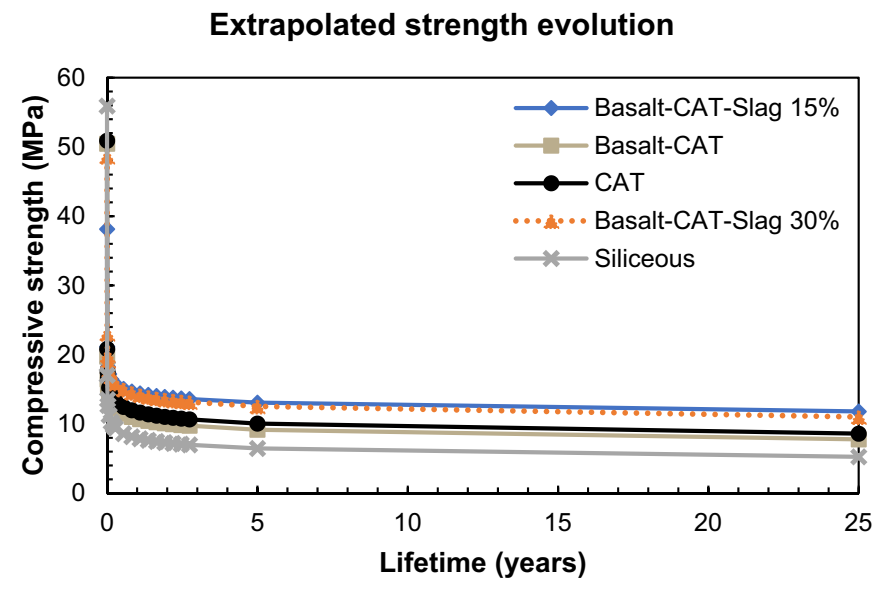

Fig. 14. Evolution of the compressive strength estimated through the experimental results of this work, considering daily thermal cycles.

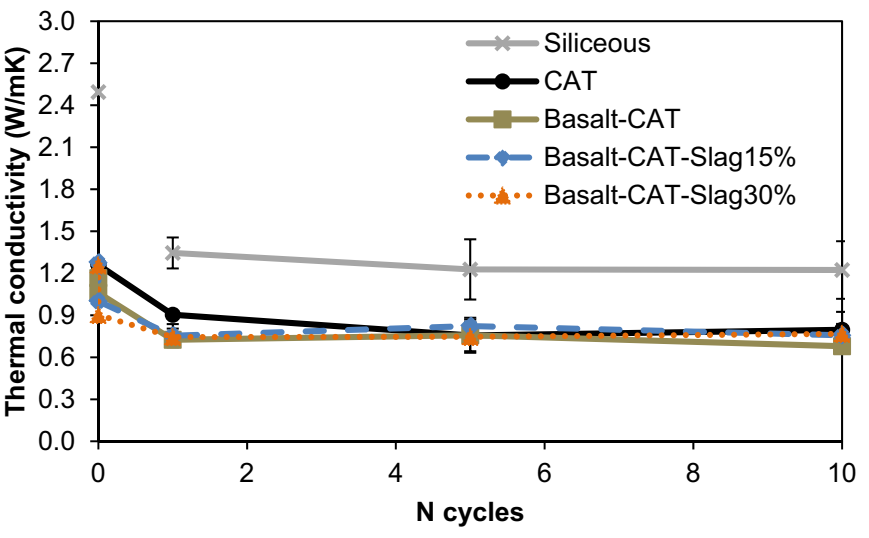

Fig. 15. Thermal conductivity variation of the concrete mixes after 1,6 , and 10 cycles: average and standard deviation values. 
Table 5

Residual values of heat capacity and diffusivity after 6 thermal cycles.

\begin{tabular}{|c|c|c|c|c|}
\hline \multirow[t]{2}{*}{ Concrete mix } & \multicolumn{2}{|c|}{$\begin{array}{l}\text { Volumetric heat capacity (J/ } \\
\left.\mathrm{m}^{3} \mathrm{~K}\right)\end{array}$} & \multicolumn{2}{|c|}{ Diffusivity $\left(\mathrm{m}^{2} / \mathrm{s}\right)$} \\
\hline & $\begin{array}{l}\text { Wet } \\
\text { conditions }\end{array}$ & $\begin{array}{l}\text { After } 6 \\
\text { cycles }\end{array}$ & $\begin{array}{l}\text { Wet } \\
\text { conditions }\end{array}$ & $\begin{array}{l}\text { After } 6 \\
\text { cycles }\end{array}$ \\
\hline CAT & $1.610 \times 10^{6}$ & $\begin{array}{l}1.660 \times \\
10^{6}\end{array}$ & $0.693 \times 10^{-6}$ & $\begin{array}{l}0.398 \times \\
10^{-6}\end{array}$ \\
\hline Basalt-CAT & - & $\begin{array}{l}1.640 \times \\
10^{6}\end{array}$ & - & $\begin{array}{l}0.369 \times \\
10^{-6}\end{array}$ \\
\hline $\begin{array}{l}\text { Basalt-CAT-Slag } \\
15 \%\end{array}$ & $1.437 \times 10^{6}$ & $\begin{array}{l}1.465 \times \\
10^{6}\end{array}$ & $0.634 \times 10^{-6}$ & $\begin{array}{l}0.445 \times \\
10^{-6}\end{array}$ \\
\hline $\begin{array}{l}\text { Basalt-CAT-Slag } \\
\quad 30 \%\end{array}$ & $1.610 \times 10^{6}$ & $\begin{array}{l}1.530 \times \\
10^{6}\end{array}$ & $0.591 \times 10^{-6}$ & $\begin{array}{l}0.401 \times \\
10^{-6}\end{array}$ \\
\hline
\end{tabular}

paste caused the loss in thermal conductivity after the first thermal cycle. This process causes a substitution of the internal water by air inside the material. The thermal conductivity of water is higher than that of the air, with values of $0.607 \mathrm{~W} / \mathrm{mK}$ and $0.02551 \mathrm{~W} / \mathrm{mK}$, respectively, at room temperature [39]. Additionally, dehydration and thermal fatigue will also produce cracks in concrete (air gaps). Consequently, dehydrated concrete will necessarily have lower thermal conductivity. Once the material suffered the first thermal cycle and the changes in its microstructure, the thermal fatigue stage does not have a relevant effect on the values of thermal conductivity measured in residual conditions.

The evolution of thermal conductivity with the temperature depends on the concrete composition and, especially, on the aggregates' type. Most studies published reported decreases in the thermal conductivity with the temperature [14,40,41], especially when using limestone or quartzite aggregates, and slight increases were reported when using lightweight aggregates [40].

The results of volumetric heat capacity indicate a small decrease of around $5-7 \%$ after the thermal cycles when compared to the values obtained in wet conditions. In comparison, thermal diffusivity decreased around $30 \%$, similar to the decrease produced in the thermal conductivity, which is consistent with the results reported in the literature [40]. The values of volumetric heat capacity and diffusivity obtained before and after 6 thermal cycles are displayed in Table 5 as an example of the variation of these properties, being the rest of the values very similar.

For concrete elements for TES applications, high thermal conductivity and stability of the aggregates are usually the desired parameters. However, heat capacity and diffusivity are also parameters of interest for some applications. While the first one gives an idea of the energy storage capacity into the material, the second quantifies the velocity of heat transport through the material. These two parameters are critical for solar energy applications because the heat source is intermittent, and the storage converts the renewable source into dispatchable energy. Therefore, concrete as a thermal energy storage material must obtain the highest amount of energy in the shortest time producing minor damage to the materials.

\section{Conclusions}

The use of concrete in Thermal Energy Storage structures can produce a significant benefit. However, it is a challenge that needs specific approaches to achieve high stability under thermal cycles at high temperatures. Using special types of binders, such as Calcium Aluminate Cement (CAC), as well as thermally stable aggregates and proper size distribution, can mitigate the drawbacks of the use of concrete at high temperatures. Based on the results presented in this work, the following conclusions can be drawn:

- The concrete mixes analyzed, excluding the siliceous mix, are recommended for thermal energy storage applications with temperatures between 290 and $550{ }^{\circ} \mathrm{C}$ (as expected in TES systems with molten salts as Heat Transfer Fluid), because of the stabilization of their thermophysical properties. More experiments are recommended to verify the long-term performance.

- Thermal cycles produced significant changes in the properties of the concrete types analyzed. The most significant degradation was produced after the first thermal cycle during the dehydration stage. After the thermal fatigue stage, the properties were only slightly degraded with each thermal cycle.

- After the thermal cycles, when using basalt, CAT, and São Domingos Slag aggregates, the compressive strength loss obtained was between 60 and $70 \%$ of the initial strength. When using siliceous aggregates, the compressive strength loss obtained was around $75 \%$. In all cases, the mass loss produced after the thermal cycles ranges between 5.5 and $6.5 \%$ of the initial mass.

- The pore size distribution obtained after the thermal cycles showed a peak of porosity in the range of $24-27 \mu \mathrm{m}$, which is related to the presence of microcracks and the vaporization of the polypropylene fibers.

- The microcracking analysis showed that the area covered by cracks remains $<1 \%$ of the area analyzed, showing maximum crack widths below $80 \mu \mathrm{m}$ after the thermal cycles performed.

- Regarding the thermal parameters, thermal conductivity decreased around $30-35 \%$ after the first thermal cycle using basalt, CAT, and São Domingos Slag aggregates. In comparison, the mix with siliceous aggregates experienced a drop of $50 \%$ of the initial conductivity. Volumetric heat capacity only experienced minor changes after the thermal cycles.

\section{CRediT authorship contribution statement}

M. Roig-Flores: Methodology, Validation, Formal analysis, Investigation, Visualization, Writing - Original Draft, Writing - Review \& Editing.

T. Lucio-Martin: Methodology, Software, Formal analysis, Investigation, Visualization, Writing - Original Draft, Writing - Review \& Editing.

M.C. Alonso: Conceptualization, Resources, Validation, Formal analysis, Writing - Original Draft, Writing - Review \& Editing, Supervision, Funding acquisition.

L. Guerreiro: Conceptualization, Resources, Writing - Review \& Editing, Funding acquisition.

\section{Declaration of competing interest}

The authors declare that they have no known competing financial interests or personal relationships that could have appeared to influence the work reported in this paper.

\section{Acknowledgments}

The research was financially supported by the H2020 project NewSol, New StOrage Latent and sensible concept for high efficient CSP Plants (Project ID: 720985). The authors would also like to thank Cement Molins for providing CAC and CAT and for the technical discussions, to Pedrera Can Saboia and, finally, to the technical support of Virtudes Flor-Laguna and Jaime Carretero Peláez from CSIC-IETcc.

\section{References}

[1] British Petroleum Company, BP Statistical Review of World Energy, 67th Edition ed., 2018.

[2] V. Devabhaktuni, M. Alam, S.S.S.R. Depuru, R.C. GreenII, D. Nims, C. Near, Solar energy: trends and enabling technologies, Renew. Sust. Energ. Rev. 19 (2013) $555-564$.

[3] A. Gil, M. Medrano, I. Martorell, A. Lázaro, P. Dolado, B. Zalba, L. Cabeza, State of the art on high temperature thermal energy storage for power generation. Part 1 - concepts, materials and modellization, Renew. Sust. Energ. Rev. 14 (1) (2010) 31-55. 
[4] D. Laing, C. Bahl, T. Bauer, M. Fiss, N. Breidenbach, M. Hempel, High-temperature solid-media thermal energy storage for solar thermal power plants, Proc. IEEE 100 (2) (2012) 516-524.

[5] E. John, M. Hale, P. Selvam, Concrete as a thermal energy storage medium for thermocline solar energy storage systems, Sol. Energy 96 (2013) 194-204.

[6] J. M. Caruncho Rodado, "System for storing Thermal Energy". Patent US 2015/ 0114593, 30 April 2015.

[7] M. Alonso, J. Vera-Agullo, L. Guerreiro, V. Flor-Laguna, M. Sanchez, M. CollaresPereira, Calcium aluminate based cement for concrete to be used as thermal energy storage in solar thermal electricity plants, Cem. Concr. Res. 82 (2016) 74-86.

[8] N. Hoivik, C. Greiner, E. Bellido Tirado, J. Barragan, P. Bergan, G. Skeie, P. Blanco, Demonstration of EnergyNest thermal energy storage (TES) technology, AIP Conference Proceedings 1850 (2017), 080011.

[9] M. Alonso, J. Puentes, Self-compacted concrete with self-protection and selfsensing functionality for energy infrastructures, Materials 13 (2020) 1106.

[10] V.A. Sötz, A. Bonk, J. Forstner, T. Bauer, Molten salt chemistry in nitrate salt storage systems: linking experiments and modeling, Energy Procedia 155 (2018) 503-513.

[11] S. Ushak, A.G. Fernández, M. Grageda, Using molten salts and other liquid sensible storage media in thermal energy storage (TES) systems, in: Advances in Thermal Energy Storage Systems, Woodhead Publishing, 2015, pp. 49-63.

[12] A. Bonk, M. Braun, V. Sötz, T. Bauer, Solar salt - pushing an old material for energy storage to a new limit, Appl. Energy 262 (2020) 114535.

[13] A.K. Galwey, G.M. Laverty, A kinetic and mechanistic study of the dehydroxylation of calcium hydroxide, Thermochim. Acta 228 (1993) 359-378.

[14] Z.P. Bažant, M.F. Kaplan, Concrete at High Temperatures: Material Properties and Mathematical Models, Addison-Wesley, London, 1996.

[15] C. Alonso, L. Fernandez, Dehydration and rehydration processes of cement paste exposed to high temperature environments, J. Mater. Sci. 39 (9) (2004) 3015-3024.

[16] H. Seleem, A. Rashad, T. Elsokary, Effect of elevated temperature on physicomechanical properties of blended cement concrete, Constr. Build. Mater. 25 (2) (2011) 1009-1017.

[17] K. Scrivener, New developments in CAC based concretes, in: 28th Conference on Our World in Concrete \& Structures, Singapore, 2003.

[18] F. Cardoso, M. Innocentini, M. Akiyoshi, V. Pandolfelli, Effect of curing time on the properties of CAC bonded refractory castables, J. Eur. Ceram. Soc. 24 (7) (2004) 2073-2078.

[19] P. Pimienta, R. McNamee, J.-C. Mindeguia, Physical properties and behaviour of high-performance concrete at high temperature, in: State-of-the-Art Report of the RILEM Technical Committee 227-HPB, Springer International Publishing, 2019.

[20] A. Bingöl, R. Gül, Compressive strength of lightweight aggregate concrete exposed to high temperatures, Indian Journal of Engineering \& Materials Sciences 11 (2004) 68-72.

[21] F. Koksal, O. Gencel, W. Brostow, H.E. Hagg Lobland, Effect of high temperature on mechanical and physical properties of lightweight cement based refractory including expanded vermiculite, Mater. Res. Innov. 16 (1) (2012) 7-13.

[22] W. Lee, W. Vieira, S. Zhang, K. Ahari, H. Sarpoolaky, C. Parr, Castable refractory concretes, Int. Mater. Rev. 46 (3) (2001) 145-167.

[23] W.N. Dos Santos, Effect of moisture and porosity on the thermal properties of a conventional refractory concrete, J. Eur. Ceram. Soc. 23 (2003) 745-755.
[24] U. Diederichs, U. Schneider, Bond strength at high temperatures, Mag. Concr. Res. 33 (115) (1981) 75-84.

[25] Z. Xing, A.-L. Beaucour, R. Hebert, A. Noumowe, B. Ledesert, Influence of the nature of aggregates on the behaviour of concrete subjected to elevated temperature, Cem. Concr. Res. 41 (2011) 392-402.

[26] Z. Xing, A.-L. Beaucour, R. Hebert, A. Noumowe, B. Ledesert, Aggregate's influence on thermophysical concrete properties at elevated temperature, Constr. Build. Mater. 95 (2015) 18-28.

[27] V.K.R. Kodur, M.A. Sultan, Effect of temperature on thermal properties of highstrength concrete, Journal of Materials in Civil Engineering March/April (101) (2003).

[28] L. Fernández-Carrasco, J. Rius, C. Miravitlles, Supercritical carbonation of calcium aluminate cement, Cem. Concr. Res. 38 (2008) 1033-1037.

[29] C. Gosselin, Microstructural Development of Calcium Aluminate Cement Based Systems with and without Supplementary Cementitious Materials, ÉCOLE POLYTECHNIQUE FÉDÉRALE DE LAUSANNE, LAUSANNE, 2009.

[30] J. Dweck, P.M. Buchler, A.C. Vieira Coelho, F.K. Cartledge, Hydration of a Portland cement blended with calcium carbonate, Thermochim. Acta 346 (1-2) (2000) $105-113$.

[31] M. Castellote, C. Alonso, C. Andrade, X. Turrillas, J. Campo, Composition and microstructural changes of cement pastes upon heating, as studied by neutron diffraction, Cem. Concr. Res. 34 (9) (2004) 1633-1644.

[32] M. Roig-Flores, M. Palacios, M. Martínez-Urbanos, M. Alonso, Influencia de aditivos orgánicos en las propiedades reológicas de pastas de cemento de aluminato de calcio, in: V Congreso Iberoamericano de Hormigón Autocompactante y Hormigones Especiales HAC 2018, 2018. Valencia.

[33] K. Scrivener, Calcium aluminate cements, in: J. Newman, B.S. Choo (Eds.), Advanced Concrete Technology, Butterworth-Heinemann, 2003, pp. 1-31.

[34] K. Nasser, J. Kenyon, Why not $3 \times 6$ inch cylinders for testing concrete compressive strength? Journal Proceedings 81 (1) (1984) 47-53.

[35] P. Kalifa, G. Chene, C. Galle, High-temperature behaviour of HPC with polypropylene fibres: from spalling to microstructure, Cem. Concr. Res. 31 (10) (2001) 1487-1499.

[36] X. Liu, G. Ye, G. De Schutter, Y. Yuan, L. Taerwe, On the mechanism of polypropylene fibres in preventing fire spalling in self-compacting and highperformance cement paste, Cem. Concr. Res. 38 (2008) 487-499.

[37] A. Luz, V. Pandolfelli, CaCO3 addition effect on the hydration and mechanical strength evolution of calcium aluminate cement for endodontic applications, Ceram. Int. 38 (2) (2012) 1417-1425.

[38] E. Horszczaruka, P. Sikora, P. Zaporowskia, Mechanical properties of shielding concrete with magnetite aggregate subjected to high temperature, in: 7th Scientific-Technical Conference Material Problems in Civil Engineering (MATBUD'2015), 2015, pp. 39-46.

[39] F.P. Incropera, D.P. DeWitt, T.L. Bergman, A.S. Lavine, Introduction to Heat Transfer, John Wiley \& Sons, 2007.

[40] U. Schneider, Concrete at high temperatures - a general review, Fire Saf. J. 13 (1988) 55-68.

[41] V. Kodur, W. Khaliq, Effect of temperature on thermal properties of different types of high-strength concrete, J. Mater. Civ. Eng. 23 (6) (2011) 793-801. 